\title{
El lugar del paisaje en la geografía moderna ${ }^{1}$ The place of the landscape in the modern geography
}

\author{
Nicolás Ortega Cantero*
}

El 16 de febrero de 1901, en la Société de Géographie de Lille, Edouard Ardaillon dio una conferencia titulada «Los principios de la geografía moderna». Ardaillon era profesor de geografía de la Universidad de esa misma ciudad, y era, además, un fiel seguidor de los renovados planteamientos promovidos, desde algunos años antes, por Vidal de la Blache, a quien consideraba «el maestro indiscutible de la ciencia geográfica francesa». Dedicó la primera parte de su conferencia a hablar de lo que no es la geografía — «la geografía», dijo, «no es lo que se nos ha enseñado en el colegio bajo el título engañoso de geografía»-, y de lo que es en realidad ese conocimiento, entendido en términos modernos, como resultado de las innovadoras aportaciones que se sucedieron en el siglo XIX, desde tiempos de Humboldt y Ritter, hasta hacer de él una verdadera «ciencia geográfica».

Luego pasó a hablar de los métodos de investigación que caracterizan a esa geografía moderna, y, para acercarse al asunto, se refirió a una «reflexión» atribuida a Vidal que le parecía «excelente», a pesar de su dudosa autenticidad: «Con libros no se hace más que geografía mediocre; la que se hace con mapas es mejor; la muy buena sólo se hace sobre el terreno». Fuese o no fuese auténtica, en esa frase se encontraba, según Ardaillon, la clave del proceder de la geografía moderna. "Es evidente, en efecto — añade-, que nada equivale a la vista y al estudio directo de los fenómenos sobre el terreno. El observador

\footnotetext{
${ }^{1}$ Este trabajo se ha realizado dentro del Proyecto de Investigación CSO2008-03877, financiado por el Ministerio de Ciencia e Innovación y el FEDER.

*Facultad de Filosofía y Letras, Universidad Autónoma de Madrid (nicolas.ortega@uam.es).
} 
ejercitado puede captar allí las múltiples relaciones entre los factores físicos y el hombre que escapan a la descripción en el libro o a la representación en el mapa. Pero no olvidéis que para ser capaces de hacer esas observaciones en vivo es necesario saber viajar y saber mirar, y eso no es ni tan común ni tan fácil como cabría imaginar» (Ardaillon, 1901, pp. 270, 281 y 285-286).

La geografía moderna se hace principalmente, por tanto, sobre el terreno, en contacto directo con la realidad, observando el mundo exterior y penetrando, a través de esa observación, en las relaciones que lo vertebran. De modo que la fisonomía de la superficie terrestre se convierte así en la clave del conocimiento geográfico. Y para acercarse a esa fisonomía, y adentrarse en lo que sus formas son y significan, en las relaciones y el orden que se expresan en ellas, hay que reunir las condiciones de las que hablaba Ardaillon: hay que saber viajar y hay que saber mirar. Se trata, en resumidas cuentas, utilizando la expresión de Marie-Claire Robic (1996), de «interrogar al paisaje». Porque el paisaje es la expresión fisonómica concreta de la realidad geográfica y del orden que la vertebra. Dicho de otro modo: los hechos geográficos — naturales y humanos-dejan huellas en la superficie terrestre, configuran un conjunto de formas y de signos, una especie de escritura, que el conocimiento geográfico debe saber mirar, es decir, debe saber leer e interpretar. Y esa superficie terrestre escrita, marcada por las huellas de los hechos geográficos, es el paisaje (Besse, 2000, pp. 102-107). No es casual, por tanto, que buena parte del conocimiento geográfico moderno se haya centrado en el paisaje. Todas las cláusulas metodológicas de ese conocimiento convergen en el paisaje: el contacto directo con el terreno, la práctica excursionista y viajera que lo hace posible, la atención preferente a las formas visibles, a la fisonomía, la decisiva importancia de la visión educada, del saber mirar, en la conformación del conocimiento. «Podríamos decir con razón —escribió Max Sorre en 1913-que toda la geografía está en el estudio del paisaje». Los demás medios de conocimiento sólo sirven, según él, para precisar, completar o rectificar las ideas procedentes del estudio directo de la realidad geográfica, de «la contemplación del paisaje» (Sorre, 1913; cf. Robic, 1996, p. 365).

La afirmación de Sorre — «toda la geografía está en el estudio del paisaje»- resume con fidelidad el modo de entender su labor de buena parte de los geógrafos modernos. Y expresa también, en consecuencia, el muy destacado lugar ocupado por el paisaje en la tradición cognitiva a la que esos geógrafos pertenecen. Acercarse al paisaje, contemplarlo, como decía Sorre, desentrañar lo que es y lo que significa, constituye, desde tiempos de Humboldt, una de las claves de la geografía moderna. Hasta podría decirse que es uno de sus más claros rasgos distintivos, y además, sin duda, uno de los as- 
pectos que se han mostrado, a lo largo del tiempo, más interesantes y más fecundos. Veamos a continuación, aunque sea brevemente, cuáles son las raíces y las razones de esa orientación paisajística de la geografía moderna, cómo y por qué se hizo del paisaje uno de sus principales objetos de conocimiento.

\section{Claves de la visión MOderna del paisaje}

El punto de partida de ese planteamiento es la atribución al paisaje de la cualidad de expresar visualmente el orden, la organización o estructura, de la realidad geográfica. No sólo de dejar ver las formas con las que se manifiesta en la superficie terrestre esa realidad geográfica, sino además, lo que es más importante, de manifestar el orden interno que las fundamenta. A través de lo exterior — las formas, la dimensión visible del paisaje — se llega a lo interior, a la organización misma que cimenta y permite explicar lo que se ve. Es lo que hizo ejemplarmente Horace-Bénédict de Saussure, cuando vio el panorama de los Alpes desde la cumbre del Mont Blanc. «No creía a mis ojos —escribe en sus Viajes a los Alpes, rememorando ese momento-, me parecía que era un sueño, cuando veía bajo mis pies esas cimas majestuosas, esas agujas temibles, el Midi, el Argentière, el Géant, cuyas mismas bases me habían ofrecido un acceso tan difícil y tan peligroso. Captaba sus relaciones, sus conexiones, su estructura, y una sola mirada resolvía dudas que no habían podido ser aclaradas con años de trabajos» (Saussure, 1981, p. 206). De eso se trataba: de captar las conexiones, las relaciones, la estructura de la realidad geográfica, y para ello era necesario ponerse en contacto directo con ella, ver el paisaje que la expresaba.

Las palabras de Saussure nos llevan a los primeros momentos del paisajismo moderno, cuando comenzó a fraguarse, en el ámbito científico y también en el del arte, un nuevo modo de ver y valorar el paisaje. Porque éste, tal y como hoy lo entendemos, es un descubrimiento moderno, directamente conectado con el romanticismo, que no fue sólo un movimiento estético, sino un horizonte mucho más amplio, vital e intelectual, cultural y científico, que renovó profundamente los modos de pensar y de sentir de su tiempo. Con el romanticismo comenzó la modernidad, de la que formaron parte, junto a manifestaciones literarias y artísticas de variada índole, concepciones científicas que promovieron, entre otras cosas, nuevas maneras de acercarse a la naturaleza y el paisaje. Junto a escritores como Rousseau o Saint-Pierre, debemos situar en esa perspectiva a naturalistas como Saussure, el estudioso de los Alpes, o Ramond de Carbonnières, con su dedicación a los Pirineos. Unos y otros abrieron, desde la segunda mitad del siglo xviII, nuevos caminos en el modo 
de entender - explicar y comprender- el paisaje, y tales novedades formaban parte de los cambios introducidos por la llegada del romanticismo, que supuso, como dijo Isaiah Berlin (2000, p. 41), «la gran transformación de la conciencia de Occidente».

Se abrió camino así, de la mano del romanticismo, un nuevo modo de entender la naturaleza y, en conexión con ella, un modo igualmente nuevo de ver y valorar el paisaje. Muchos factores confluyeron para hacer posibles esas novedades. Numa Broc se refirió a algunos de ellos: en el mundo del arte, el nacimiento de un nuevo clima estético y sentimental, que se proyectó hacia el paisaje — se ha podido decir que La nueva Eloísa de Rousseau hizo derramar «lágrimas geográficas» a las almas sensibles-, y en el terreno científico, el notable desarrollo del conocimiento de la naturaleza, promovido por las ciencias naturales y la geografía física, y asociado en ocasiones a los grandes viajes de exploración (Broc, 1991, pp. 15-20).

A esto último hay que añadir otro aspecto importante: el surgimiento, al tiempo que se avanzaba en ese conocimiento, de una nueva concepción de la naturaleza como totalidad ordenada, como conjunto internamente vertebrado, y del paisaje como expresión fisionómica, visible, de la organización natural. Sobre este asunto, verdaderamente significativo respecto de la conformación del paisajismo moderno, habló también Saussure en sus Viajes a los Alpes. Reprochó a la mayoría de los viajeros naturalistas de su tiempo que se contentasen con «recoger curiosidades», que caminasen con «los ojos fijos en la tierra», recolectando «trocitos», sin preocuparse de las observaciones generales. «Recuerdan - añade - a un anticuario que rascara la tierra en Roma, en medio del Panteón o del Coliseo, para buscar allí fragmentos de vidrio coloreado, sin echar un vistazo a la arquitectura de estos soberbios edificios». Hay que pasar, según Saussure, de lo fragmentario a lo general, de los detalles al conjunto, de la curiosidad analítica a la visión sintética. Ésa es la única manera de entender la verdadera entidad de la naturaleza, es decir, su carácter de conjunto ordenado. Sin descuidar las observaciones de detalle, hay que procurar, concluye, no perder de vista los conjuntos, no olvidar que el estudio de las partes debe tener siempre como finalidad «el conocimiento de los grandes objetos y sus relaciones» (Saussure, 1779-1796; cf. Ortas Durand, 1999, pp. 119-120).

Pero hay más. No sólo se introdujo la idea de orden, de organización, en la concepción de la naturaleza, sino que se consideró además que ese orden era de índole orgánica, biológica. La naturaleza no es un mecanismo, como se había supuesto con anterioridad, aplicando un razonamiento metafórico de cuño newtoniano, sino un ser vivo, un organismo. Es una totalidad, un conjunto, y su orden es el de la vida, no el de la máquina. «La naturaleza, consi- 
derada por medio de la razón—escribió Humboldt—, es decir, sometida en su conjunto al trabajo del pensamiento, es la unidad en la diversidad de los fenómenos, la armonía entre las cosas creadas, que difieren por su forma, por su propia constitución, por las fuerzas que las animan; es el Todo animado por un soplo de vida» (Humboldt, 1874-1875, t. I, p. 3). Esta concepción organicista de la naturaleza entraña algunas consecuencias que conviene tener en cuenta. Toda forma orgánica visible es la expresión de un significado subyacente, de un contenido interior invisible. La principal aportación de la concepción organicista es, como ha advertido Besse, lograr la reconciliación del hecho (la forma) y el sentido (el orden interno), o, dicho de otro modo, de la naturaleza y el espíritu (Besse, 1992, pp. 107-109). Todo hecho está espontáneamente dotado de un sentido que se expresa en la forma de ese hecho. La naturaleza está dotada, por tanto, de un sentido que se expresa en sus formas, las formas naturales. Forma y sentido se unen así en la concepción romántica de la naturaleza. Por eso fueron tan importantes las formas - y el método morfológico- en el horizonte romántico (y también en la geografía moderna): porque a través de ellas, como recordó Vincent Berdoulay (2000, pp. 32-36), se puede explicar y comprender el mundo.

De manera que las formas de la naturaleza, las manifestaciones naturales visibles, expresan su orden interno, su sentido. Y esas formas constituyen justamente el paisaje, que se entiende así, por tanto, como la expresión visible del orden natural. Ésta es la clave del nuevo modo de ver y valorar el paisaje promovido por la modernidad romántica. El principal empeño de los artistas y científicos de entonces fue conocer la naturaleza, entender su orden y su sentido -o, como decía Humboldt (1874-1875, t. I, p. 3), penetrar en sus «misterios», descubrir sus «secretos»-, y el modo de adentrarse en ese conocimiento pasaba por la visión del paisaje. Porque en él se expresan, se hacen visibles, ese orden y ese sentido naturales. Es, por decirlo así, la cara -espejo del alma- de la naturaleza. Constable dijo que pintar el paisaje era lo mismo que investigar las leyes de la naturaleza (Constable, 1970; cf. Gage, 2002, p. 39). Y Humboldt, por su parte, afirmó que el simple contacto con el paisaje hace posible «el presentimiento del orden y de las leyes» que presiden la naturaleza (Humboldt, 1874-1875, t. I, p. 4).

Hay dos aspectos más, estrechamente conectados con lo anterior, que conviene tener en cuenta para terminar de caracterizar el horizonte intelectual en el que se inscribió el paisajismo moderno. En primer lugar, el fundamento visual de su propuesta cognitiva. El conocimiento del paisaje, en términos artísticos y científicos, se resuelve a través de la visión, de la experiencia visual. Hay que ver —o, mejor, saber ver- el paisaje para lograr entenderlo, para lle- 


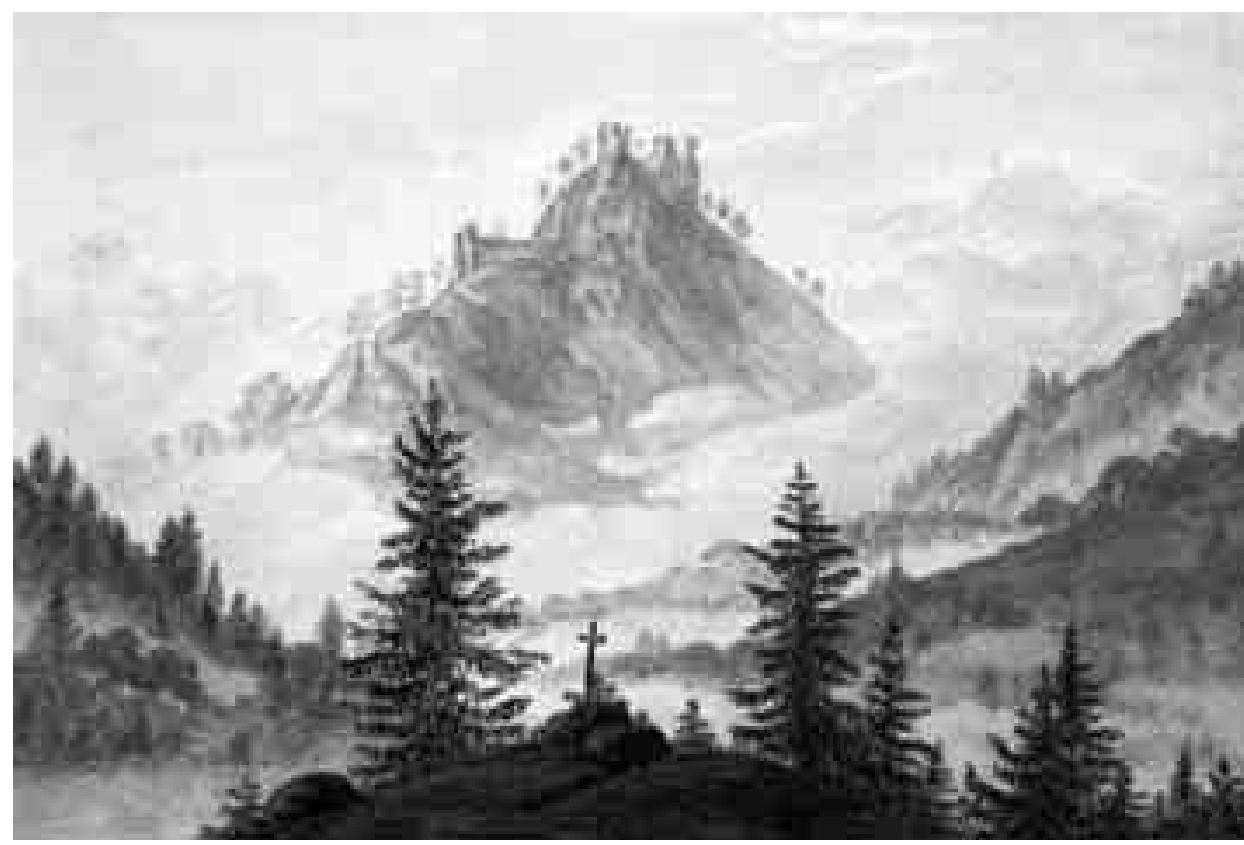

Pincel y sepia, $12,2 \times 18,2 \mathrm{~cm}$.

gar a explicar sus formas y comprender sus significados. Y esa preeminencia de lo visual no hace sino manifestar la coherente inserción de esta perspectiva paisajística en el panorama artístico y científico de su tiempo. «Para conocer un objeto - se decía, en 1886, en la primera circular de la Sociedad para el estudio del Guadarrama, fundada en el seno de la Institución Libre de Enseñanza-, es indispensable verlo de algún modo, y tanto más claro y a conciencia es el conocimiento, cuanto más directa, inmediata y viva es la vista de las cosas» (Institución Libre de Enseñanza, 1886, p. 367). La fórmula no resume mal la pauta metodológica que se impuso en el ámbito naturalista y geográfico moderno desde la segunda mitad del siglo xviII, que supuso la entronización de la experiencia visual como fundamento del conocimiento (tanto artístico como científico). Hay que estudiar la naturaleza «en la naturaleza misma y no en los cuadros», decía Friedrich (Hinz, 1968; cf. Schuster, 1992, p. 44). La vista adquirió una gran importancia como «instrumento de 
conocimiento» en el siglo XIX, y ello fue así, como advirtieron Vincent Berdoulay y Hélène Saule-Sorbé, no sólo en el terreno de la ciencia, sino también, a la vez, en el del arte, lo que favoreció el acercamiento entre uno y otro, desmintiendo supuestas oposiciones entre ambos, y traduciéndose a menudo en formas de complementariedad valiosas y fecundas. La obra de Humboldt fue, en este sentido, verdaderamente ejemplar. El saber no es ahora, por tanto, anterior a la mirada, sino posterior, y no se sitúa ya en el terreno de la proyección, sino en el de la percepción (Berdolulay y Saule-Sorbé, 1998, pp. 41-42). Y el conocimiento geográfico moderno, con su predilección por el paisaje, se inscribió plenamente en ese marco. La geografía moderna se presenta ante todo, en palabras de Besse (2000, p. 111), como «un arte de la percepción visual».

El segundo aspecto se refiere a las vías de conocimiento que hay que aplicar para lograr entender el paisaje. En la medida en que éste entraña forma y sentido, materialidad y valores, debe ponerse en juego, para entenderlo, un conocimiento capaz de afrontar tales dimensiones constitutivas. Es decir, hay que explicar, por una parte, las formas del paisaje, sus características y sus relaciones, la organización que las vertebra conjuntamente, y hay que comprender, por otra, sus cualidades y significados, sus valores y su sentido. Hay que aunar, en suma, la explicación y la comprensión, la ciencia y el arte, la razón y el sentimiento. Hace falta movilizar miradas cognitivas diversas y complementarias. Y de su convergencia efectiva depende precisamente la posibilidad de entender cabalmente el paisaje. A lo más objetivable, al estudio de la materialidad del paisaje, hay que añadir la visión más subjetiva, la que procura adentrarse en el mundo de la atribución de valores y cualidades inmateriales. Y ambas facetas son necesarias — simultáneamente necesarias - para conformar la imagen del paisaje, atendiendo a lo que es y a lo que significa. Las dos perspectivas están presentes en los fundadores del paisajismo moderno, tanto en los que se mueven en el terreno del arte -escritores, pintores-, como en los que pertenecen al campo de la ciencia. Rousseau, por ejemplo, se interesó por la botánica —fue, según Humboldt (1874-1875, t. II, p. 63), un herborizador «más cuidadoso que instruido a decir verdad»-, y se ha dicho que en su obra «se aúna el examen detallado de la naturaleza con propósitos científicos y la impresión personal ante lo contemplado» (Ortas Durand, 1999, p. 121). Y algo parecido cabe decir de los científicos que comenzaron a acercarse con criterios modernos al paisaje. Saussure, por ejemplo, que confesaba que la vista del Mont Blanc le producía «una especie de emoción dolorosa» (Saussure, 1981, p. 217), supo añadir a su mirada naturalista, geológica, una indudable sensibilidad artística: a lo largo de su obra aparecen «una preocupación científica y un sentimiento estético estrechamente mezclados» (Joutard, 1986, p. 125). 
Para entender el paisaje, hay que hermanar, por tanto, la mirada científica y la artística, hay que explicar las cosas, pero también hay que comprenderlas. O, con palabras de Humboldt (1874-1875, t. II, p. 69), buscar la convergencia del «rigor de la ciencia» y el «soplo vivificador de la imaginación». La visión moderna del paisaje entraña así una vertiente que atañe a la naturaleza, a su dimensión natural, conectada con la explicación, y otra que remite a la cultura, al proceso subjetivo de atribución de valores culturales, relacionada con la comprensión. Junto a su caracterización natural, sus formas materiales y objetivas, el paisaje ofrece significados culturales que deben ser muy tenidos en cuenta en todo momento: ignorarlos «es mutilar el paisaje tan gravemente como pudiera serlo la tala de un bosque, el derribo de un pueblo» (Martínez de Pisón, 2009, p. 43).

\section{EL PAISAJISMO GEOGRÁFICO}

Todo lo anterior permite hacerse una idea de las notas fundamentales del nuevo modo de entender el paisaje alentado, desde la segunda mitad del siglo XVIII, por la modernidad romántica. Esa visión del paisaje, con sus intenciones explicativas y comprensivas, arraigó en el mundo del arte y en el de la ciencia, y constituyó, sin duda, uno de los aspectos más innovadores y valiosos del horizonte intelectual promovido por esa modernidad. Se fraguó así el paisajismo moderno, la nueva manera de ver y valorar el paisaje, simultáneamente apoyada en la razón y en el sentimiento, que se manifestó, en principio, en dos ámbitos principales: el del arte, el de los escritores y los pintores, y el de la ciencia, el de los naturalistas y los geógrafos físicos. Todos ellos compartieron ese nuevo modo de entender el paisaje, y coincidieron igualmente en la intención de tener en cuenta al tiempo la mirada científica y la artística, la explicación y la comprensión, a la hora de verlo y valorarlo, por más que, como es lógico, la importancia relativa concedida a cada una de ellas fuese distinta en unos casos (los artistas) y en otros (los científicos). Rousseau o Constable no carecieron de curiosidad naturalista en sus acercamientos al paisaje, y Saussure o Ramond no eludieron en los suyos el sentimiento.

Fue precisamente en ese horizonte intelectual —y paisajístico- en el que nació la geografía moderna. Humboldt y Ritter, sus fundadores, incorporaron los renovados planteamientos de ese horizonte, incluyendo, claro está, su concepción de la naturaleza y su modo de entender el paisaje. La geografía moderna recogió así la perspectiva paisajística de cuño romántico que había comenzado a fraguarse en la segunda mitad del siglo XviII, pero no se limitó a 
recogerla pasivamente, sino que participó muy activamente en su prolongación y su enriquecimiento, haciendo del paisaje una de las finalidades principales de su estudio. Las aportaciones de Humboldt son, en este sentido, sumamente elocuentes. No se contentó con incorporar las nuevas perspectivas paisajísticas, sino que contribuyó además a desarrollarlas y a configurar, en el seno de la naciente geografía moderna, una orientación paisajística vigorosa y fecunda.

Humboldt recibió una educación que aunó la perspectiva del humanismo clásico y la del conocimiento naturalista, ampliamente desarrollado a través de sus estudios de minería y de los contactos que mantuvo con los círculos naturalistas alemanes y franceses de su tiempo. También estuvo directamente conectado con el primer romanticismo alemán, uno de los más tempranos y valiosos del panorama europeo. En la formación de Humboldt como geógrafo y como paisajista, fue importante la estrecha relación que mantuvo con el naturalista, viajero y escritor Georg Forster, acompañante del capitán Cook en su segundo viaje alrededor del mundo. Humboldt consideró a Forster su «maestro y amigo», elogió su «sentimiento exquisito hacia las bellezas naturales» y su capacidad para llegar hasta lo más «verdadero» —es decir, lo más ajustado a la verdad científica- en sus descripciones de la naturaleza (Humboldt, 1874-1875, t. II, p. 68), y encontró en él un verdadero modelo de cómo ver y valorar el paisaje, aunando la intención científica y la artística. Y todo ese aprendizaje se apoyó en la experiencia viajera que ambos compartieron. Humboldt viajó con Forster por Europa — por Alemania, a lo largo del Rin, por Inglaterra y Francia- y con él aprendió, como señaló Charles Minguet, «a observar el paisaje, a distinguir con rapidez sus rasgos esenciales, y a describirlos después con arte y precisión». Aprendió a acercarse al paisaje, y aprendió también a representarlo, a ofrecer de él una imagen literaria fidedigna, del mismo modo que lo había hecho, en sus Cuadros del bajo Rin, de 1791, el propio Forster, «un maestro —añade Minguet (1969, p. 42) — en materia de descripción científica y artística».

Después, entre 1799 y 1804, realizó Humboldt el viaje más importante de su vida, el viaje a la América española, del que se nutrió casi toda su obra geográfica y paisajística. Partió hacia América, junto al botánico francés Aimé Bonpland, en junio de 1799, desde el puerto de La Coruña, hizo una escala en Tenerife, donde permaneció una semana y subió al Teide, y llegó en julio a Cumaná. Estuvo en Venezuela, en Cuba, en Colombia, en Perú y en México, siguió el curso del Orinoco, recorrió buena parte de la cordillera andina, en la que prestó gran atención a los volcanes, y, tras una estancia de tres meses en los Estados Unidos, regresó a Europa, a Burdeos, en agosto de 1804. De ese largo viaje se nutrió la experiencia paisajística de Humboldt, de la que dio 
cuenta sobre todo en dos obras tempranas y cercanas en el tiempo: los Cuadros de la Naturaleza, de 1808, y las Vistas de las cordilleras y monumentos de los pueblos indígenas de América, de 1810, dentro estas últimas de la serie que recoge los resultados del viaje americano.

Las aportaciones de Humboldt están directamente conectadas con la obra de Saussure. Le conoció personalmente en Ginebra, en 1795, durante un viaje por Italia y Suiza, leyó y elogió en diversas ocasiones su obra, y dijo de él que había sido «el más sabio e intrépido de los viajeros» (Humboldt, 1878, p. 63). Humboldt recogió el legado de Saussure, con su visión predominantemente científica, explicativa, del paisaje, pero recogió también, al tiempo, el legado de Rousseau, con su paisajismo de signo predominantemente artístico, estético y comprensivo. En los paisajistas anteriores, en Rousseau o en Saussure, se había producido ya, como dijimos antes, una cierta convergencia de la explicación y la comprensión, de la mirada científica y la artística, aunque con un claro predominio, distinto según los casos, de una de esas dos dimensiones. La singularidad del paisajismo geográfico de Humboldt, que seguramente no hubiese sido posible sin su amplitud de miras y su sólida formación naturalista y humanista al tiempo, fue encontrar un nuevo modo de relación entre la explicación y la comprensión del paisaje. Humboldt era geógrafo, un geógrafo muy interesado por los aspectos físicos o naturales, heredero - «su verdadero heredero espiritual», según Numa Broc (1991, p. 274)— de Saussure, y por ello su manera de acercarse al paisaje se enmarca en el ámbito de la ciencia, buscando describirlo y explicarlo. Y a esa vertiente científica y naturalista añade Humboldt otra de carácter artístico, que, en su caso, adquiere una notable importancia. El sentimiento y la comprensión del paisaje, predominantes en el mundo del arte - la literatura, la pintura-, y presentes también, aunque de manera más tenue, en el de la ciencia, ocupan un lugar destacado en el paisajismo geográfico de Humboldt, que conforma así una relación más equilibrada, más armónica, entre las dos dimensiones puestas en juego.

Resultan en este sentido muy elocuentes sus Cuadros de la Naturaleza, la obra que abrió el camino del nuevo paisajismo geográfico. El propio Humboldt señaló, tanto en el prólogo de su primera edición, como en el que añadió en la tercera y definitiva, de 1849, que la doble finalidad de su libro era «hacer más sensibles, con ayuda de pinturas vivas, los goces de la naturaleza», y, al tiempo, descubrir, hasta donde los avances científicos permitían hacerlo, «la acción conjunta y armoniosa de las fuerzas que animan el mundo». Para lograrlo, añadía, había procurado aunar la estética y la historia natural, las intenciones literarias y los fines científicos, con «el deseo de cautivar la imaginación y enriquecer la vida con ideas y conocimientos nuevos» (Humboldt, 
1990, t. I, p. 5). Cuando se publicó la traducción francesa de los Cuadros de la Naturaleza, el editor advirtió expresamente la capacidad de su autor para lograr la convergencia equilibrada de la explicación científica y la comprensión artística: era, decía, una obra maestra, que ofrecía la suma de Bernardin de Saint-Pierre y la exactitud de la ciencia (Humboldt, 1990, t. I, p. XXVIII). Humboldt era un científico destacado y, además, un buen escritor, dotado de sensibilidad literaria y de una notable capacidad expresiva, y ambas cualidades hicieron posible su modo de entender el paisaje y de representarlo, aunando la intención explicativa y la comprensiva, la razón y el sentimiento. Algo que se ha prolongado después en los mejores exponentes del paisajismo geográfico moderno, igualmente empeñados en hermanar la explicación y la comprensión, como puede comprobarse, por ejemplo, en las visiones del paisaje de Élisée Reclus o Paul Vidal de la Blache.

A lo largo de las páginas de los Cuadros de la Naturaleza, se encuentran coherentemente incorporadas y aplicadas, a propósito de los grandes modelos naturales y paisajísticos que había encontrado en América, las claves del paisajismo moderno, y se manifiesta además con nitidez esa capacidad de Humboldt para lograr, en su visión geográfica del paisaje, la convergencia equilibrada de la explicación y la comprensión, de la razón científica y el sentimiento artístico. Frente al predominio de lo artístico en el paisajismo de escritores como Rousseau y Saint-Pierre, y al de lo científico en el promovido por naturalistas como Saussure y Ramond, Humboldt propone una visión geográfica del paisaje que se caracteriza, en suma, por ofrecer una relación mucho más equilibrada, mucho más armónica, entre ambas dimensiones. Basta leer, para comprobarlo, las imágenes de ofrece de las cataratas de Atures y Maipures, en el Orinoco, que visitó durante su recorrido a lo largo de ese río, en 1800, para estudiar su discutida conexión con el Amazonas a través del Casiquiare (Humboldt, 1990, t. I, pp. 257-289).

Desde 1807, y a lo largo de más de veinte años, publicó Humboldt los treinta volúmenes del Viaje a las regiones equinocciales del Nuevo Continente, en los que expuso los resultados de su recorrido americano. Dos de esos volúmenes - el XV y el XVI-, titulados Atlas pintoresco del viaje o Vistas de las cordilleras y monumentos de los pueblos indígenas de América, ofrecen también un importante contenido paisajístico. Esta obra tiene además la ventaja de incluir a la vez imágenes literarias y gráficas, textos y grabados, de los paisajes americanos incluidos, que permiten establecer algunas relaciones y comparaciones entre ambas formas de representación.

Las Vistas comprenden sesenta y nueve grabados y otros tantos comentarios de lo representado en ellos. Era, como ha indicado Jean-Paul Duviols, un 
planteamiento sin precedentes, ya que Humboldt no entendía los grabados como una mera ilustración de los textos, sino «como un testimonio científico y como una demostración», de modo que «texto e imagen dialogan y se complementan de forma nueva y convincente» (Duviols, 1989, p. XV). Parte de esos grabados y comentarios tratan de aspectos monumentales, y los demás se refieren a aspectos paisajísticos. De estos últimos, dos remiten a Canarias, primera etapa del viaje de Humboldt, y los restantes ofrecen vistas de algunos de los paisajes americanos que recorrió, con una presencia muy destacada de los andinos, de índole montañosa y volcánica. Allí están algunos de los lugares paisajísticamente más destacados de la cordillera de los Andes: las cascadas de

\section{FIGURA 2}

PASO DEL QUINDÍO, EN LA CORDILLERA DE LOS ANDES (ALEXANDRE DE HUMBOLDT: VUES DES CORDILLËRES ET MONUMENTS DES PEUPLES INDIGĖNES DE L'AMÉRIQUE, 1810, LÁMINA 5)

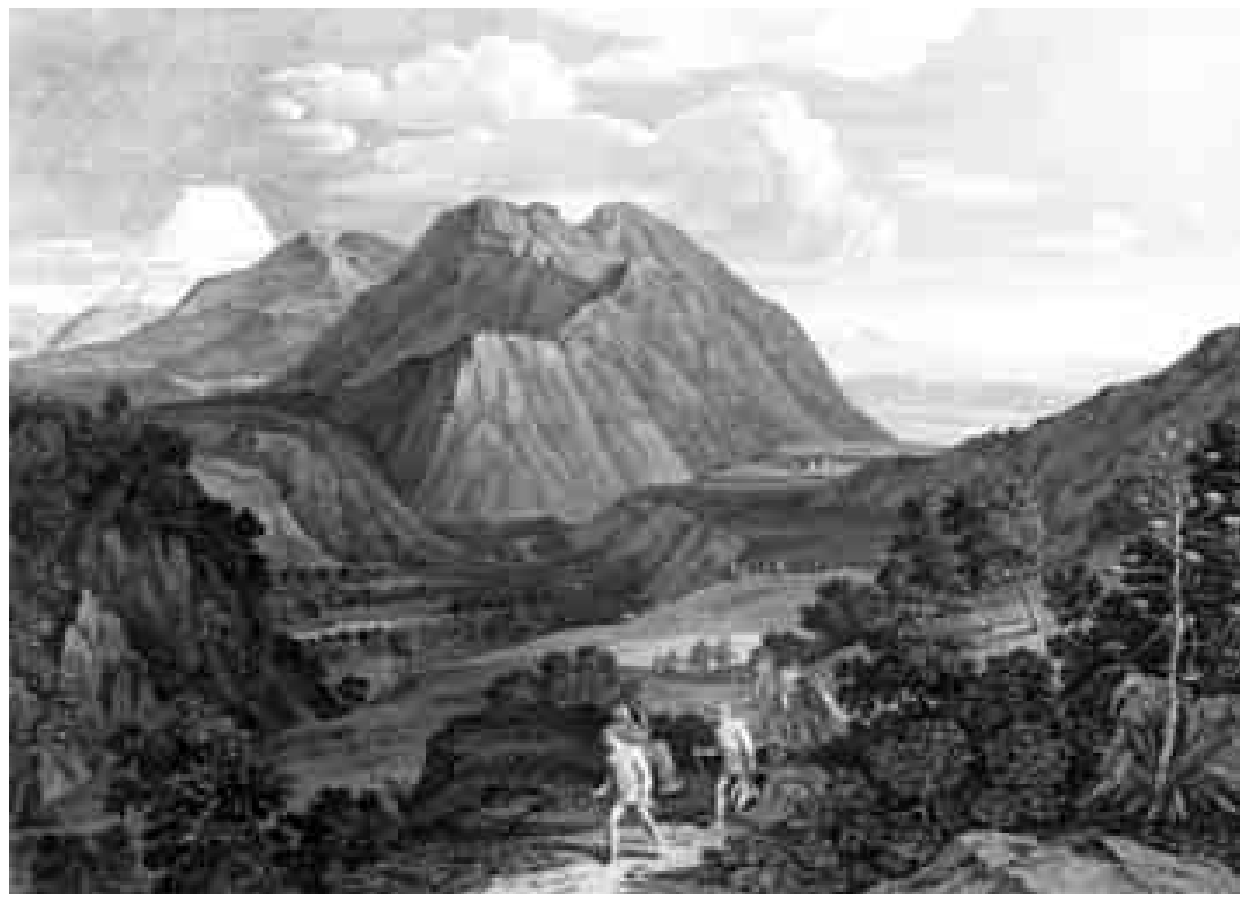

Grabado en cobre de Ch. T. Duttenhofer, según un dibujo de J. A. Koch, basado en un boceto de A. von Humboldt.

Estudios Geográficos, Vol. LXXI, 269, pp. 367-393, julio-diciembre 2010 ISSN: 0014-1496, eISSN: 1988-8546, doi: 10.3989/estgeogr.201012 
Tequendama y del río Vinagre, los puentes naturales de Icononzo y el paso del Quindío, y los grandes volcanes del sector ecuatoriano: Cotopaxi, Chimborazo, Carguairazo, Cayambé, Pichincha.

La doble dimensión explicativa y comprensiva está siempre presente en las imágenes del paisaje incluidas en las Vistas, tanto en las literarias como en las contenidas en los grabados. En estas últimas, en las imágenes gráficas, Humboldt apoya la visión descriptiva y explicativa, como ha señalado Hélène Saule-Sorbé, en los procedimientos del denominado «paisaje compuesto», de modo que, siguiendo tradiciones paisajísticas y pictóricas anteriores, y partiendo de los estudios del natural, el autor sigue un proceso de «selección-clasificación-composición» que le permite construir una imagen que organiza y explica los componentes y las relaciones de la realidad paisajística considerada (Saule-Sorbé, 2006, pp. 67-72). Esa visión científica, analítica y explicativa, se acompaña en los grabados de Humboldt de la mirada comprensiva, que busca captar y expresar las cualidades del paisaje, la dimensión estética y sentimental de lo que se representa. Las Vistas ofrecen muchas y valiosas muestras de esa manera de entender el paisaje. Así sucede ejemplarmente, por poner un ejemplo, en la imagen de la cascada de Tequendama, que «reúne cuanto pide un sitio para ser eminentemente pintoresco», donde, tras hablar de la caracterización física del salto — «no existe cascada alguna que presente igual proporción entre la altura considerable y gran masa de agua»-, precisada gracias a sus observaciones - «he conseguido trasportar instrumentos a la quebrada misma, al pie de la cascada»—, se refiere Humboldt a la impresión que produce: «Apenas si la luz del día penetra en esta grieta; y la soledad del sitio, la riqueza de la vegetación y espantoso ruido que se percibe, convierten este lugar de la cascada de Tequendama en uno de los más salvajes de las Cordilleras» (Humboldt, 1878², pp. 41-44).

${ }^{2}$ La traducción española de Bernardo Giner que aquí se cita (Sitios de las cordilleras y monumentos de los pueblos indígenas de América, 1878) no responde a la versión original de la obra de Humboldt (Vues des cordillères et monuments des peuples indigènes de l'Amérique, 1810). Recoge una segunda reducción de ésta, publicada en francés en 1869 , cambiando en el título el término Vues por el de Sites, que incluyó sólo 10 de las 69 ilustraciones contenidas en la edición de 1810, alteró, en consecuencia, los comentarios, y modificó el orden de la exposición, pasándose del inicial a otro con agrupación geográfica de los asuntos tratados. El resultado mutila significativamente la aportación de Humboldt, sobre todo en lo que se refiere a su dimensión gráfica, sin duda fundamental, y su interés queda muy por debajo del que caracteriza a aquélla. En el momento de escribir estas líneas, se está ultimando la publicación, por parte de Marcial Pons Ediciones y de la Universidad Autónoma de Madrid, de la primera traducción en España de la edición original e íntegra de las Vistas de Humboldt, con todos sus grabados. 
La influencia del paisajismo geográfico de Humboldt fue notable, y no sólo en el terreno de la geografía. Llegó hasta ámbitos muy dispares del panorama cultural decimonónico. Se dejó sentir, por ejemplo, entre los pintores de paisaje, y alguno de ellos, como el norteamericano Frederic Edwin Church, «fascinado» por la lectura de sus obras, se dedicó a viajar y a pintar en tierras americanas siguiendo sus huellas (García Felguera, 2000). De la impresión que produjeron en el mundo de la pintura las imágenes del paisaje de Humboldt, puede dar idea el siguiente comentario de Carus, naturalista, pintor y amigo de Friedrich: « ¿Quién no ha sentido al narrador henchido de visión directa por todos los costados cuando Humboldt [...] pinta con palabras ante nuestras almas sus cuadros de las estepas y de las gigantescas cataratas de América?» (Carus, 1992, p. 126).

Con las obras mencionadas - los Cuadros de la Naturaleza y las Vistas de las cordilleras y monumentos de los pueblos indígenas de América-, Humboldt abrió la puerta al paisajismo geográfico moderno, un paisajismo interesado al tiempo en explicar el paisaje y en comprenderlo, en acercarse a lo que el paisaje es y a lo que significa. Ésa es la visión del paisaje, el modo de entender el paisaje, que adoptó la geografía moderna, y que constituyó sin duda una de sus aportaciones más interesantes, valiosas y fecundas. El punto de vista geográfico participó así en la conformación del paisajismo moderno. Fue un punto de vista valioso e influyente, un enfoque que podemos considerar intermedio entre el de los artistas y el de los científicos naturalistas, que compartió con ellos la convicción de que para entender el paisaje es necesario aunar la ciencia y el sentimiento, y que procuró además que esa unión fuese más equilibrada, más armónica, que en las perspectivas paisajísticas respectivamente asociadas a ellos.

Como he indicado en otro lugar (Ortega Cantero, 2004, pp. 28-35), esa perspectiva paisajística conformada inicialmente por Humboldt se prolongó después, en los siglos XIX y Xx, en la tradición geográfica moderna. Se mantuvo la doble intención explicativa y comprensiva, prestando atención, en consecuencia, tanto a las formas, a la materialidad visible, a los hechos objetivables, como a las cualidades y los significados, al orden interno, a la atribución subjetiva de sentido. Decía Baulig que «el geógrafo no se contenta con descomponer los complejos naturales, con desmontarlos, desplegarlos (explicare); se propone también captarlos, comprenderlos en su complejidad y describirlos como tales». Esos complejos se le presentan «en forma de aspectos, de paisajes», y son precisamente esos paisajes los que procura describir razonadamente, explicativamente, la geografía, manteniendo la doble perspectiva —explicativa y comprensiva, artística y científica- que adoptó desde sus comienzos modernos (Baulig, 1948, pp. 9-10). 


\section{HABLAR DEL PAISAJE}

El nuevo paisajismo de cuño romántico que se abrió camino, como hemos visto, desde la segunda mitad del siglo XvIII supuso, en buena medida, un descubrimiento del paisaje. El paisajista moderno, cualquiera que fuese su procedencia, artística o científica, tenía que enfrentarse a un mundo nuevo, a un panorama inédito, y además tenía que dar cuenta de lo que había descubierto en él. Necesitaba saber ver el paisaje, y necesitaba al tiempo saber expresar lo que había visto en él. Y para ello debía contar con el lenguaje adecuado, con un lenguaje capaz de dar cuenta de todas las novedades -intelectuales y sentimentales- que la experiencia moderna del paisaje entrañaba. La conformación de un nuevo modo de entender el paisaje exigía la simultánea conformación de un lenguaje también nuevo - o renovado-que pudiera satisfacer sus necesidades expresivas. En el mundo de la pintura, por ejemplo, hubo que configurar un nuevo lenguaje pictórico. Cuando Goethe, en 1775, en el Puente del Diablo del valle suizo del Reuss, intentó dibujar el paisaje alpino del San Gotardo, hubo de reconocer que carecía del «lenguaje» apropiado para «tales objetos» (Goethe, 1944-1945, t. 2., p. 1434). Y en el ámbito de la literatura — sin excluir la de cuño científico-, fue necesario también vertebrar lenguajes nuevos. Se refirió a ello poco antes, en 1772, Bernardin de Saint-Pierre (1840, p. 104): «El arte de representar la naturaleza es tan nuevo, que los términos todavía no han sido inventados».

La necesidad de formar un lenguaje apropiado para hablar del paisaje se sintió en todos los ámbitos del paisajismo moderno, tanto en los más inclinados hacia los puntos de vista naturalistas y científicos, como, sobre todo, en los de intención más artística. La literatura y la pintura de paisaje ofrecen en este sentido muestras muy elocuentes de esa búsqueda de nuevos lenguajes. Lo mismo sucedió en el terreno del paisajismo geográfico moderno, que tuvo que enfrentarse igualmente a la configuración de un nuevo lenguaje, y de una retórica —una retórica paisajística - que ayudase a utilizar ese lenguaje del mejor modo posible. Porque se trataba no sólo de conformar un léxico apropiado, sino también de decidir cómo vertebrar internamente el texto, de qué manera dosificar sus componentes ideológicamente más significativos, y de establecer además qué procedimientos literarios convenía poner en juego. A la hora de intentar entender las claves retóricas del paisajismo geográfico moderno, debemos tener en cuenta esos tres ámbitos distintos y complementarios: el ámbito léxico, el de las palabras mismas, el ámbito de la organización del texto, referente a la disposición en su interior de los componentes ideológicamente significativos, y el ámbito de los procedimientos literarios utilizados. 
El paisajismo moderno tuvo que conformar un nuevo vocabulario que respondiese a los nuevos modos de pensar y sentir el paisaje. Una parte importante de ese nuevo léxico fue de índole estética, e incorporó igualmente otros términos de carácter científico. Además del léxico capaz de dar cuenta de la comprensión del paisaje, de su sentimiento estético, hacía falta otro que pudiera resolver la parte explicativa, la dimensión más científica del discurso paisajístico. La incorporación de ese léxico científico fue muy patente en el paisajismo de montaña. El fuerte atractivo que ejercieron, desde la segunda mitad del siglo XVIII, los Alpes y los Pirineos, explorados y estudiados respectivamente por Saussure y Ramond, se tradujo en la proliferación de términos científicos que designaban las formas y los fenómenos naturales de la montaña y, más concretamente, del mundo glaciar.

El vocabulario del paisajismo geográfico moderno incorporó plenamente esos dos ámbitos léxicos: por una parte, el de índole científica, naturalista, que le resultaba muy cercano, y, por otra, el de carácter estético, artístico. Ambos formaron parte del vocabulario conformado por la geografía moderna para hablar del paisaje. La obra paisajística de Humboldt es, en ese sentido, elocuente. Desde el punto de vista léxico, podemos encontrar en ella, junto a un nutrido y preciso vocabulario científico (naturalista y geográfico), un amplio repertorio de términos estéticos, que dan buena cuenta de la incorporación por parte de Humboldt del nuevo lenguaje acuñado por el paisajismo artístico moderno. En las páginas iniciales de las Vistas de las cordilleras y monumentos de los pueblos indígenas de América, al resumir las finalidades perseguidas en los grabados y en los comentarios de carácter expresamente paisajístico, dice Humboldt, por ejemplo, que quiere dar a conocer las «grandes escenas» de la naturaleza americana, prestando atención al «contorno de las montañas, los valles que las surcan y las imponentes cascadas que forma la caída de los torrentes», y al «efecto pintoresco que pueda resultar de la contemplación de este espectáculo». Allí, en las cordilleras americanas, se encuentra reunido, añade, cuanto de «romántico o grandioso» ha visto antes en otros paisajes de Europa. Ha recorrido a lo largo de su viaje americano sitios que considera «majestuosos», y los ha recorrido procurando siempre «observar las bellezas y descubrir las maravillas allí prodigadas» (Humboldt, 1878, p. 23).

Los términos empleados indican con bastante claridad la plena incorporación por parte de Humboldt de las novedades léxicas del paisajismo artístico moderno. Pero no fue ése su único mérito en ese terreno, ya que contribuyó además directamente a enriquecer el vocabulario correspondiente a la visión moderna del paisaje. Oscar Peschel se refirió a la extraordinaria maestría literaria de Humboldt, a «la fuerza maravillosamente creadora de la expresión 
humboldtiana», apoyada precisamente en un vocabulario acuñado en buena medida por él mismo. «Con una palabra afortunada y atrevida —escribe Peschel- pintaba Humboldt el carácter de una forma o de una cosa» (cf. Beck, 1971, p. 259). La destreza léxica de Humboldt, que se manifestó en su manera de incorporar los vocabularios del paisajismo moderno y de enriquecerlos, constituyó un factor importante de la retórica en la que se apoyó su representación literaria del paisaje.

Otro aspecto importante de la retórica del paisajismo moderno es la manera de organizar dentro del texto sus dimensiones descriptiva y sentimental. La primera comprende todos los términos y enunciados que remiten a la visión explicativa o científica, mientras que la segunda abarca los que introducen la mirada comprensiva, la que atañe más directamente a la vertiente estética y artística. Aun estando ambas presentes en todas las versiones del paisajismo moderno, la importancia adquirida por cada una de ellas varía mucho, como apuntamos anteriormente, de unos casos a otros. El paisajismo moderno se mueve entre las retóricas que optan por el predominio de lo descriptivo y las que, en el extremo opuesto, sitúan lo sentimental en primer término. Humbodlt era consciente de esa dualidad, y lo era también de la conveniencia de conciliar de manera armónica sus dos componentes para lograr entender el paisaje de manera cabal.

A Humboldt le interesaba encontrar un modo de relación equilibrado entre ambas dimensiones que respondiese a las intenciones de la geografía. Quería ofrecer imágenes del paisaje en las que estuviesen presentes la razón y la inteligencia, y que fuesen también capaces de expresar, al tiempo, el sentimiento y la imaginación. Ése es el equilibrio entre ciencia y estética, entre lenguajes descriptivos y sentimentales, entre objetividad y subjetividad, que buscaba Humboldt para resolver, en términos geográficamente convincentes, la representación del paisaje. Era un equilibrio difícil, pero no imposible. Había que conformar una retórica del paisaje que aunase ambas perspectivas (descripción y sentimiento) sin caer en los vicios que acechan en sus extremos: el descripcionismo y el sentimentalismo.

A lo largo de sus escritos, Humboldt elaboró - y puso en práctica- una retórica del paisaje bien justificada y definida. Sus reflexiones del segundo tomo del Cosmos no sólo ofrecieron una interpretación en clave naturalista y geográfica de la historia del paisajismo artístico — literario y pictórico-, sino que mostraron además, al referirse al paisajismo de intención más científica que habían promovido los «observadores de la naturaleza» de su tiempo, su propia concepción de lo que debía ser la visión geográfica del paisaje y, en relación con ello, de las claves retóricas que convenía poner en 
juego para representarla y comunicarla. Las imágenes literarias del paisaje debidas a esos observadores de la naturaleza — viajeros y naturalistas casi siempre- pretendían, en palabras de Humboldt, «hacer comprensibles por medio del lenguaje, es decir, por la fuerza inherente a la palabra pintoresca, los resultados de su fecunda contemplación». Pero ese propósito no siempre se había resuelto felizmente en términos literarios. Muchos de sus autores se habían dejado llevar, dice Humboldt, por el «malhadado gusto hacia una prosa poética sin consistencia y a vanas declamaciones», defecto que se agravaba todavía más «cuando el narrador, falto de cultura literaria, y sobre todo desprovisto de verdadera emoción, tiene que reducirse al énfasis oratorio y a un vago sentimentalismo». Como se ve, Humboldt no confundía el paisajismo naturalista y geográfico con el estrictamente literario, pero creía, con razón, que el primero requería una cierta «cultura literaria», un dominio del lenguaje y de las formas de expresión suficiente para comunicar adecuadamente por escrito su visión del paisaje.

Propone Humboldt finalmente algunos criterios para conformar el horizonte retórico del paisajismo geográfico, y, más concretamente, para organizar las dimensiones descriptiva y sentimental de su discurso. Señala ante todo la necesidad de buscar la convergencia armónica de tales dimensiones, de aunar la ciencia y la imaginación, y añade que la fuerza expresiva de la imagen del paisaje depende principalmente de la capacidad de su autor para plasmar «el lazo que une el mundo intelectual al mundo sensible», y para abarcar «la vida universal de la naturaleza», el orden y la unidad que la caracterizan. Para todo ello es imprescindible estar familiarizado con el lenguaje y sus posibilidades, dominar las claves de la escritura: el verdadero paisajista — y geógrafo— debe evitar lo que Humboldt denomina «el adorno exterior del lenguaje», y debe dominar «los recursos de su lengua» y saber «expresar con verdad y sencillez cuanto ha experimentado ante las escenas de la naturaleza» (Humboldt, 1874-1875, t. II, pp. 69-70). Esos son, según Humboldt, los criterios para conformar una retórica del paisaje que responda a las intenciones de la geografía moderna y a su característico empeño en simultanear de forma equilibrada la intención descriptiva y explicativa y la sentimental y comprensiva. Y esos fueron los criterios a los que se atuvo él mismo en las numerosas imágenes literarias del paisaje, siempre logradas y en ocasiones modélicas, que ofreció a lo largo de su obra.

El tercer aspecto que hay que tener en cuenta para delimitar las claves retóricas del paisajismo geográfico moderno es el que se refiere a los procedimientos literarios que utiliza, que comprenden múltiples recursos, desde las construcciones sintácticas, los tipos de enunciados y las formas verbales y de 
adjetivación, hasta las maneras de concretar los ritmos narrativos. Con todos esos ingredientes se configura el estilo literario del texto, su modo concreto de expresión. Es éste un asunto sin duda interesante e importante, del que depende en buena medida la capacidad comunicativa del discurso geográfico, su eficacia para transmitir adecuadamente las ideas y las imágenes que pone en juego. Así lo demuestran los estudios que se han llevado a cabo hasta ahora en esta dirección.

Los procedimientos literarios utilizados en el discurso geográfico moderno varían de unos autores a otros, y evolucionan sensiblemente a lo largo del tiempo, por lo que vamos a considerar aquí únicamente los que manifiestan una cierta continuidad y funcionan como cláusulas de estilo ampliamente aceptadas. Es lo que sucede, en el ámbito del paisajismo moderno, incluyendo el de signo geográfico, con los modos de expresión acuñados por la literatura de viajes, que se mostraron especialmente adecuados para dar cuenta de una experiencia paisajística que sólo era posible a través del desplazamiento, de la movilidad del observador. La literatura de viajes facilitaba la expresión de la experiencia personal del paisaje, de los sentimientos provocados en el viajero por los lugares contemplados. Era una forma de expresión literaria particularmente indicada para comunicar experiencias personales, para dar cuenta de las impresiones y vivencias originadas por el acercamiento al paisaje. Esas cualidades expresivas acercan la literatura de viajes a otras modalidades literarias también idóneas para la comunicación de impresiones, sentimientos y vivencias, como son las conectadas con la escritura de cartas y diarios, que también se emplearon con cierta frecuencia, a veces asociadas a la perspectiva viajera, en el paisajismo moderno.

Los procedimientos de la literatura de viajes han sido utilizados en muchas de las representaciones literarias modernas del paisaje, incluyendo las geográficas. Las obras de Humboldt resultan sumamente elocuentes en ese sentido, y el paisajismo geográfico posterior siguió apoyándose habitualmente en esos mismos procedimientos. Esta utilización de los procedimientos de la literatura de viajes en la representación geográfica moderna del paisaje se halla directamente conectada, claro está, con la importancia adquirida por la experiencia visual como instrumento de conocimiento. El modo moderno de entender el paisaje se apoya en el contacto directo, inmediato, con él, pero ese acercamiento no debe ser estático, inmóvil, sino que requiere, como ya indicó con claridad Humboldt, conjugar puntos de vista diferentes y complementarios, desplazarse físicamente, pero también, al tiempo, moverse en términos intelectuales, ir de unos campos del conocimiento a otros, cruzar las fronteras que separan el mundo científico del artístico. El viaje es el medio más ade- 
cuado para facilitar las condiciones de contacto visual y de desplazamiento (ante todo, físico, pero también, de manera menos directa, intelectual) requeridas por el paisajismo moderno.

La representación panorámica del paisaje, procedimiento habitual en la literatura de viajes, adquirió una notable importancia en el discurso geográfico moderno. Su interés se basaba sobre todo en la posibilidad que ofrecía para conformar imágenes de conjunto, unitarias, en las que se recogiesen tanto los diversos componentes formales del paisaje, como las relaciones — proximidades, lejanías, contrastes, continuidades, agrupamientos, oposiciones, complementariedades - que cabe distinguir entre ellos. La imagen panorámica ofrece así una posibilidad muy valiosa de presentar los rasgos característicos del paisaje, las notas que definen las líneas maestras de su organización. La perspectiva panorámica mejora la visión del paisaje, y lo hace no sólo en términos cuantitativos, sino también cualitativos. No sólo se ve más desde la cumbre de una montaña, sino que se ve mejor; no sólo se amplía la visión, sino que se ahonda; no sólo se ven las cosas, sino las relaciones entre las cosas. Todo ello hace de la visión panorámica un recurso fundamental en la retórica moderna del paisaje.

Las vistas panorámicas abundan en el paisajismo geográfico. Para los geógrafos modernos, la visión panorámica del paisaje llegó a constituir una verdadera cláusula de estilo, habitual en sus escritos. Las Vistas de las cordilleras y monumentos de los pueblos indígenas de América son, también en este sentido, sumamente elocuentes. Su modelo narrativo es el de la literatura de viajes, que se corresponde con la experiencia viajera que fundamenta toda la obra. En conexión con ello, se encuentra la frecuente utilización de la visión panorámica, que permite expresar el orden del paisaje, señalar sus principales componentes y la organización que definen conjuntamente a través de sus relaciones. A modo de ejemplo, cabe recordar aquí las geográficamente magistrales vistas panorámicas que ofrece del ámbito andino del Chimborazo desde la meseta de Tapia, imponente espectáculo de cuya grandeza sólo pueden formarse idea quienes «hayan contemplado de cerca el espectáculo que ofrecen las cimas del Mont-Blanc y el Mont-Rose», o de los puentes naturales de Icononzo, una valiosa muestra de las escenas «varias y majestuosas que ofrecen las Cordilleras», un acabado ejemplo de los valles andinos, más profundos y estrechos que los de los Alpes y los Pirineos, que «se presentan como sitios salvajes a propósito para causar admiración y aun espanto», donde destaca Humboldt «la extraordinaria forma de sus rocas que parecen talladas de mano humana» y «lo árido y pelado de sus cimas», que «contrasta pintorescamente con la abundante vegetación de los bordes de la quebrada» (Humboldt, 1878, pp. 45-46 y 65). 


\section{FIGURA 3}

PAISAJE DE PRADERAS Y VIÑEDOS DE REMBERCOURT, LORENA (PAUL VIDAL DE LA BLACHE: LA FRANCE. TABLEAU GÉOGRAPHIQUE, 1908, FIGURA 20)

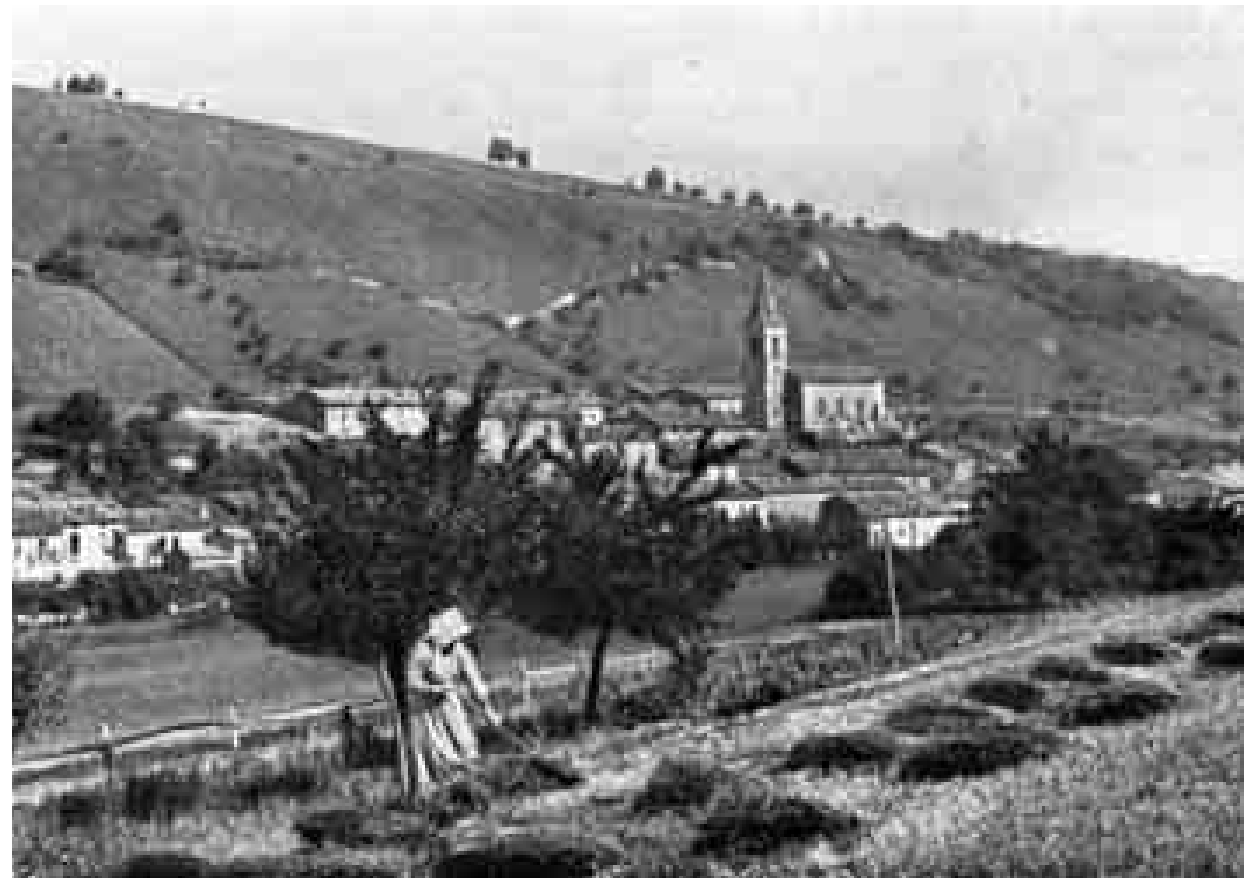

Fotografía: Col. P. Michels, Nancy.

La utilización de los procedimientos de la literatura de viajes se ha mantenido a lo largo de la tradición geográfica y paisajística posterior a Humboldt, como demuestran, entre muchas otras, las aportaciones de Reclus o Vidal de la Blache. Algunas obras del primero son auténticos libros de viajes —el relato de su recorrido por la Sierra Nevada de Santa Marta, sus historias del arroyo y de la montaña-, y los procedimientos de ese tipo de literatura se encuentran también presentes en otros trabajos suyos. Y Vidal de la Blache incorpora igualmente esos procedimientos en sus escritos. El Tableau de la géographie de la France no sólo plasma la experiencia viajera de su autor, sino que además se ajusta con bastante fidelidad a los modos expresivos de la literatura de viajes de su tiempo. Su prosa descriptiva adopta, como han demostrado los análisis lingüísticos de Jean-Louis Tissier (2000), los procedimientos característicos 
de los libros de viajes de su época - por ejemplo, la utilización frecuente de un «personaje-observador» (el viajero), o el uso habitual de enunciados que expresan un «efecto de viaje»—y de ese modo se logra hacer de su lectura «una especie de viaje virtual».

Humboldt, Reclus y Vidal de la Blache aportan, en suma, ejemplos significativos y valiosos de la utilización de los procedimientos de la literatura de viajes por parte del paisajismo geográfico moderno. Y, al igual que ellos, otros muchos geógrafos modernos han apoyado su visión del paisaje en esa experiencia viajera y han utilizado los procedimientos de esa literatura de viajes para representarla a través de la escritura. Veamos, por último, otro ejemplo muy expresivo en ese sentido: el que ofrece el geógrafo francés Emmanuel de Martonne en su lectura geográfica del paisaje de los Alpes.

La experiencia viajera tuvo siempre una gran importancia en el quehacer geográfico de De Martonne, tanto en su vertiente docente como en su proyección escrita. Su escritura - la escritura de un geógrafo físico- se caracteriza por su orientación técnica, por su sobriedad y por su precisión. Ello no quiere decir, sin embargo, que sea una escritura despersonalizada, carente de subjetividad, exclusivamente empeñada en dar cuenta de los hechos. Como ha indicado Olivier Orain, De Martonne también moviliza ocasionalmente, casi siempre con maestría, los recursos propiamente literarios de la escritura, que se incorporan a su discurso eminentemente descriptivo y realista para proporcionarle «efectos de realidad» capaces de «engendrar en el lector un proceso de fusión con el referente» (Orain, 2001, p. 304). Y entre esos recursos se cuentan la introducción, como en el Tableau de Vidal, del "personajeobservador» y del «efecto de viaje» en el texto. Es lo que hace De Martonne cuando inscribe en el escenario paisajístico del que está hablando un testigo ocular, uno de esos «innumerables y rituales espectadores» de sus descripciones a los que se refiere Orain —viajero, turista, alpinista, geólogo-, que, además de favorecer el «efecto de viaje» en el texto, facilita la identificación del lector con la experiencia excursionista o viajera en la que se apoya su discurso geográfico.

La obra que dedicó De Martonne a los Alpes - Los Alpes. Geografía general, de 1926- ofrece una buena muestra de la utilización de esos recursos literarios. Es un texto sencillo y lúcido, escrito con inteligencia y claridad de ideas y propósitos, en el que predomina, como en toda la obra del autor, la dimensión científica y explicativa, sin que ello suponga la ausencia del componente estético y comprensivo. De Martonne no es indiferente a las cualidades del mundo alpino, a «los contrastes violentos» que le proporcionan «su carácter agreste y su belleza». Habla de «los panoramas grandiosos ofrecidos por la alta 
montaña», de las «formas pintorescas» del paisaje alpino, de su «encanto»y de su «inagotable variedad de aspectos», de las diversas «impresiones» que despierta su naturaleza (De Martonne, 1955, pp. 19, 22, 56 y 58). Y la presencia del «personaje-observador» y del «efecto de viaje» se deja ver una y otra vez en el texto. A propósito del relieve, por ejemplo, dice: «Por el esfuerzo de los músculos, por la tensión de los nervios, el alpinista mide lo que significa un desnivel de varios miles de metros. Al habitante de las llanuras que aborda por primera vez los Alpes le es difícil apreciar la distancia que separa los muelles del Isère en Grenoble y los picos de Belledone, la terraza de la Grave y la cumbre resplandeciente del Meije, o los grandes hoteles de Zermatt y la punta del Cervino» (De Martonne, 1955, p. 13).

De ese modo se manifiesta la presencia de la experiencia viajera en el texto sobre los Alpes de De Martonne, presencia que aparece de modo similar, por lo demás, en todo su discurso geográfico. Y conviene añadir, para terminar, que esa presencia no sólo se deja sentir en términos estrictamente literarios, sino también incluso en la presentación de los componentes iconográficos de su discurso. En la obra geográfica de De Martonne, aparece en ocasiones una disposición del contenido iconográfico — gráficos y fotografías- que expresa también, a su manera, la presencia de la experiencia viajera. Es una característica que, como ha advertido Didier Mendibil (1999, p. 328), se halla bastante generalizada en los textos de los geógrafos modernos, cuya iconografía pretende a menudo «ilustrar o simular un viaje explícito». En la parte dedicada en 1942 a la geografía física de Francia en la Geografía Universal dirigida por Vidal de la Blache y Gallois, por ejemplo, De Martonne muestra el circo pirenaico de Gavarnie mediante tres vistas fotográficas sucesivas que se van aproximando progresivamente, disposición que, como señala Mendibil (2006, p. 182), «sugiere un acercamiento al lugar extraído del álbum de fotos de un excursionista». De ese modo se incorpora también la experiencia excursionista y viajera a la iconografía que acompaña al discurso geográfico de De Martonne. Al igual que sucede con la vertiente textual, literaria, del discurso geográfico de De Martonne, su componente iconográfico expresa con frecuencia su directa y estrecha conexión con la experiencia viajera.

Todo lo que se ha expuesto hasta aquí puede ayudar a entender los rasgos más destacados del modo de entender el paisaje promovido por la geografía moderna. Su visión es integradora, no separativa: quiere explicar y comprender al tiempo, prestar atención a la vez a la dimensión natural y a la dimensión cultural del paisaje. Es una visión apoyada en todo momento en la observación, en el contacto directo con el paisaje, y apoyada asimismo, por tanto, en la experiencia viajera que hace posible esa observación, ese con- 
tacto. Es, en fin, una visión que se expresa finalmente a través de la escritura, de las imágenes literarias, en las que el geógrafo da cuenta de su experiencia del paisaje, estrechamente conectada con su experiencia viajera. Y ese discurso paisajístico de los geógrafos modernos incorpora regularmente los procedimientos de la literatura de viajes, procurando mejorar así su capacidad para comunicar cabalmente las experiencias - experiencia del viaje, experiencia del paisaje- a las que se refiere. Todo ello resulta significativo para caracterizar el lugar — destacado lugar- ocupado por el paisaje en la tradición geográfica moderna.

Recibido: 22/07/2010

Aceptado: 23/09/2010

\section{BIBLIOGRAFÍA}

Ardaillon, E. (1901): "Les principes de la géographie moderne", Bulletin de la Société de Géographie de Lille, XXII, 4, pp. 269-290.

Baulig, H. (1948): "La géographie est-elle une science?", Annales de Géographie, LVII, 305, pp. 1-11.

Beck, H. (1971): Alexander von Humboldt; traducción de Carlos Gerhard. México D. F., Fondo de Cultura Económica.

Berdoulay, V. (2000): "Le milieu, entre description et récit. De quelques difficultés d'une approche de la complexité", en Vincent Berdoulay y Olivier Soubeyran (dirs.): Milieu, colonisation et développement durable. Perspectives géographiques sur l'aménagement. París y Montréal, L'Harmattan, pp. 25-37.

Berdolulay, V. y Saule-Sorbé, H. (1998): "La mobilité du regard et son instrumentalisation. Franz Schraeder à la croisée de l'art et de la science", Finisterra, XXXIII, 65, pp. 39-50.

Berlin, I. (2000): Las raíces del romanticismo; edición de Henry Hardy, traducción de Silvina Marí. Madrid, Taurus.

Besse, J.-M. (1992): "Entre modernité et postmodernité: la représentation paysagère de la nature", en Marie-Claire Robic (dir.): Du milieu à l'environnement. Pratiques et représentations du rapport homme/nature depuis la Renaissance. París, Economica, pp. 89-121.

Besse, J.-M. (2000): "La physionomie du paysage, d'Alexandre de Humboldt à Paul Vidal de La Blache", en Voir la Terre. Six essais sur le paysage et la géographie. Arles, Actes Sud, ENSP, Centre du Paysage, pp. 95-114.

Broc, N. (1991): Les montagnes au siècle des lumières. Perception et représentation. París, Comité des travaux historiques et scientifiques. 
Carus, C. G. (1992): Cartas y antotaciones sobre la pintura de paisaje; traducción de José Luis Arántegui, introducción de Javier Arnaldo. Madrid, Visor.

Constable, J. (1970): John Constable's discourses; compiled and annotated by R. B. Beckett. Ipswich, Suffolk Records Society.

Duviols, J.-P. (1989): “Alexandre de Humboldt et l'image de l'Amérique”, en Alexandre de Humboldt: Vues des cordillères et monuments des peuples indigènes de l'Amérique. Nanterre, Éditions Erasme, pp. XV-XVIII.

Gage, J. (2002): "Le paysage est ma maîtresse", en Constable. Le choix de Lucian Freud. París, Réunion des Musées Nationaux, pp. 35-45.

García Felguera, M. de los S. (2000): "Church y el paisaje tropical", en Explorar el Edén. Paisaje americano del siglo XIX. Madrid, Museo Thyssen-Bornemisza, pp. 153-154.

Goethe, J. W. (1944-1945): De mi vida. Poesía y Verdad, en Obras literarias; traducción, recopilación, prólogo y notas de R. Cansinos Assens. Madrid, M. Aguilar, 2 t., t. 2, pp. 1045-1459.

Hinz, S. (1968): Caspar David Friedrich, in Briefen und Bekenntnissen. Berlín, Henschelverlag.

Humboldt, A. de (1874-1875): Cosmos. Ensayo de una descripción física del mundo; vertido al castellano por Bernardo Giner y José de Fuentes. Madrid, Imprenta de Gaspar y Roig, Editores, 4 t.

Humboldt, A. de (1876): Cuadros de la Naturaleza; traducción de Bernardo Giner. Madrid, Imprenta y Librería de Gaspar, Editores.

Humboldt, A. de (1878): Sitios de las cordilleras y monumentos de los pueblos indígenas de América; traducción de Bernardo Giner. Madrid, Imprenta y Librería de Gaspar, Editores.

Humboldt, A. de (1989): Vues des cordillères et monuments des peuples indigènes de l'Amérique; études et introductions de Charles Minguet et Jean-Paul Duviols. Nanterre, Éditions Erasme.

Humboldt, A. de (1990): Tableaux de la Nature; traduction de M. Ch. Galuski, études et introductions de Charles Minguet et Jean-Paul Duviols, index bibliographique de Philippe Babo. Nanterre, Éditions Européennes Erasme, 2 t.

Institución Libre de Enseñanza (1886): "La nueva Sociedad para el estudio del Guadarrama", Boletín de la Institución Libre de Enseñanza, X, 236, pp. 367-368.

Joutard, P. (1986): Linvention du mont Blanc. París, Gallimard-Julliard.

Martínez de Pisón, E. (1998): "El concepto de paisaje como instrumento de conocimiento ambiental", en Eduardo Martínez de Pisón (dir.): Paisaje y medio ambiente. Valladolid, Universidad de Valladolid y Fundación Duques de Soria, pp. 9-28.

Martínez de Pisón, E. (2009): Miradas sobre el paisaje. Madrid, Biblioteca Nueva.

Martonne, E. de (1955): Los Alpes (Geografía general); traducción de Joaquina Comas Ros. Barcelona, Juventud. 
Mendibil, D. (1999): "Essai d'iconologie géographique", L'Espace Géographique, XXVIII, 4, pp. 327-336.

Mendibil, D. (2006): "Iconografía geográfica de los paisajes de Francia: contextos, formatos, posiciones", en Nicolás Ortega Cantero (ed.): Imágenes del paisaje. Madrid, Universidad Autónoma de Madrid y Fundación Duques de Soria, 2006, pp. 149-197.

Minguet, C. (1969): Alexandre de Humboldt, historien et géographe de l'Amérique espagnole, 1799-1804. París, François Maspero.

Orain, O. (2001): "Emmanuel de Martonne, figure de l'orthodoxie épistémologique postvidalienne?", en Guy Baudelle, Marie-Vic Ozouf-Marignier y Marie-Claire Robic (dirs.): Géographes en pratiques (1870-1945). Le terrain, le livre, la Cité, Rennes, Presses Universitaires de Rennes, pp. 289-311.

Ortas Durand, E. (1999): Viajeros ante el paisaje aragonés (1759-1850). Zaragoza, Institución Fernando el Católico (CSIC).

Ortega Cantero, N. (2004): "Naturaleza y cultura en la visión geográfica moderna del paisaje", en Nicolás Ortega Cantero (ed.): Naturaleza y cultura del paisaje, Madrid, Universidad Autónoma de Madrid y Fundación Duques de Soria, 2004, pp. 9-47.

Robic, M.-C. (1996): "Interroger le paysage? L'enquete de terrain, sa signification dans la géographie humaine moderne (1900-1950)", en Claude Blanckaert (dir.): Le terrain des sciences humaines. Instructions et Enquêtes (XVIII-XXe siècle). París y Montréal, LHarmattan, pp. 357-388.

Saint-Pierre, B. de (1840): Voyage à l'île-de-France, en Bernardin de Saint-Pierre: Oeuvres. París, Ledentu, Librairie-Éditeur, pp. 17-124.

Saule-Sorbé, H. (2006): "Ante la prueba del motivo artístico: algunas reflexiones sobre la observación en el arte del paisaje", en Nicolás Ortega Cantero (ed.): Imágenes del paisaje. Madrid, Universidad Autónoma de Madrid y Fundación Duques de Soria, pp. 49-100.

Saussure, H. B. de (1779-1796): Voyages dans les Alpes, précédés d'un Essai sur l'histoire naturelle des environs de Genève. Neuchâtel, Samuel Fauché, 4 t.

Saussure, H. B. de (1981): Premières ascensions au Mont-Blanc, 1774-1787; introduction de Roger Canac. París, François Maspero.

Schuster, P.-K. (1992): "Las soledades de Caspar David Friedrich sobre su vida y su obra", en Caspar David Friedrich. Pinturas y dibujos. Madrid, Museo del Prado, pp. 34-49.

Sorre, M. (1913): Les Pyrénées méditerranéennes. Étude de géographie biologique. París, Armand Colin.

Tissier, J.-L. (2000): "Le voyage, filigrane du Tableau de la géographie de la France?", en Marie-Claire Robic (dir.): Le Tableau de la géographie de la France de Paul Vidal de la Blache. Dans le labyrinthe des formes, París, Comité des travaux historiques et scientifiques, pp. 19-31. 


\section{RESUMEN}

El paisaje ha ocupado un lugar destacado en la geografía moderna. Desde sus comienzos, a principios del siglo XIX, la tradición geográfica moderna ha hecho del paisaje uno de sus principales objetos de conocimiento, y ha procurado, al estudiarlo, incorporando el legado romántico, aunar de forma equilibrada la intención explicativa y la comprensiva. La importancia del paisaje en la geografía moderna se ha manifestado además en términos retóricos, en la conformación de discursos capaces de expresar adecuadamente la experiencia paisajística.

PALABRAS ClaVE: paisaje; geografía moderna; explicación; comprensión; retórica.

\section{AbStract}

The landscape has occupied an outstanding place in the modern geography. From its origins, at the beginning of the 19th Century, the modern geographic tradition has done of landscape one of its main objects of knowledge, and it has tried, when studying it, incorporating the romantic legacy, to combine in a well-balanced form the explanatory intention and the comprehensive one. The importance of the landscape in the modern geography has been stated also in rhetorical terms, in the conformation of discourses able to expressing properly the landscape's experience.

KEY WORDS: landscape; modern geography; explanation; understanding; rhetoric.

\section{RÉSUMÉ}

Le paysage a occupé une place importante dans la géographie moderne. Depuis ses débuts, au début du siècle XIX, la tradition géographique moderne a fait du paysage un de ses principaux objets de connaissance, et a essayé, en l'étudiant, en incorporant le legs romantique, unir de manière équilibrée l'intention explicative et ce qui est compréhensive. Limportance du paysage dans la géographie moderne s'est manifestée en outre en termes rhétoriques, dans la conformation de discours capables d'exprimer adéquatement l'expérience paysagistique.

MoTS CLÉs: paysage; géographie moderne; explication; compréhension; rhétorique. 